\title{
ASSESSING THE RISK FACTORS OF WORK-RELATED STRESS AMONG HOUSE OFFICERS OF TERTIARY CARE HOSPITALS, KARACHI
}

\author{
Zulfiqar Ali Shaikh ${ }^{1}$, Noshaba Noor ${ }^{2}$, Aisha Farooq ${ }^{3}$, Maryam Khaleel ${ }^{4}$, Darakhshan Naqvi ${ }^{5}$, Usama Ahmed ${ }^{6}$, \\ Huzefa Ahmed ${ }^{7}$, Fareha Shakil ${ }^{8}$, Javeria Shamim ${ }^{9}$, Javaria Asif ${ }^{10}$, Sarah Khan ${ }^{11}$, Hafiz Ali Abbas ${ }^{12}$
}

${ }^{1}$ Professor, Community Medicine, Dow Medical College/DUHS, Karachi

${ }^{2-5,8-12}$ Final Year MBBS, Dow Medical College/DUHS, Karachi

${ }^{6} 3$ rd Year MBBS, Karachi Medical and Dental College

${ }^{7} 4$ th Year MBBS, Sindh Medical College, Karachi

Correspondence: ZulfiqarAli Shaikh, Email: drzulfiqarshaikh@gmail.com

\begin{abstract}
Background: House Officers report significant levels of work-related stress that demands to be immediately addressed as it adversely affects their ability to function their best as doctors. This study aimed to assess the risk factors of psychological distress among the currently working house officers (2016-2017).

Objectives: To assess the various risk factors of work-related stress amongst the house officers working in tertiarycare hospitals, Karachi

Methods: A cross sectional study was carried out in Civil Hospital, Jinnah Postgraduate Medical Centre and Abbasi Shaheed Hospital, Karachi during October 2016 and March 2017. A total of 384 house officers were approached for the study as per the sample size calculated using the Open-epi software. The questionnaire comprised of demographic data, 10-items perceived stress scale, and 12-items list of potential stressors. The severity of each stressor was measured using a five-point Likert scale (1-5) ranging from always (1) to never (5).

Results: A total of 384 house officers were approached out of whom 315 (82\%) participated. Among them, 115 $(36.50 \%)$ were found to be under stress of whom 24 (20.8\%) were males and 91(79.2\%) were females. Significant difference for stressors by gender was found, these included their job having an effect on their health, change in eating habits and lack of paramedical staff cooperation $(P<0.05)$. Factors like increased hesitancy to take on tasks and increased tendency to make errors were found to have an impact on clinical performance ( $P$ value $<0.05)$.

Conclusion: There is high level of perceived stress in house officers of tertiary care hospitals, Karachi. Therefore, adequate steps are needed for stress management which should be dealt in terms of preventive rather than curative strategy.
\end{abstract}

Keywords: Stress, house officers, tertiary care hospitals, stressors, performance

\section{Introduction}

Stress, anxiety and depression are closely related, and modify the quality of outcome in any profession, hence originates the issue of job-dissatisfaction. Since Medicine is considered a stressful field, it is crucial to identify and control the job-related stress, especially when it comes to healthcare personnel, so that they may serve the suffering humanity in the best possible way $(1,4)$. The stress among doctors cannot and should not be neglected because the health of not one, but two parties is at stake, one being the doctor him/herself, and the other being the patient and his family. The nature of job and the quality of work matter a lot in terms of achievement of goals (1). Provision of optimum health care at tertiary hospitals contribute to better health outcomes and this could be possible if the environment and the doctor him/herself are stress-free. The doctors' level of job satisfaction influences the nature of the health care and the services they provide, the patientdoctor relationship and even the compliance to and effectiveness of the prescribed treatment. All of these ultimately lead to a profound impact on the patient's health $(1,2,3,4)$. Stress creates obstacles in the healthcare system at all levels; and the house officers who have recently started their career are frequent victims. This adversely affects their ability to function their best as doctors, thus creating serious psychosocial problems both for the healthcare providers and also the patients $(1,3,4)$.

When stress reaches a level where it begins to impair a doctor's capability to work properly, it leads to serious consequences even to the point where the patient's life may be endangered (3). Many probable causative factors have been identified, some of which are the work 
overload, sleep deprivation, treatment failure, etc. $(1,2,3)$. A study was formulated in Germany which dealt with identifying the various causes of self-reported depression in junior doctors (5). In Malaysia, a study comprising of 42 house officers found that $31 \%$ of them were suffering from stress (6). Another research in three university hospitals of Saudi Arabia found $73 \%$ of the interns suffering from stress, the majority of them were females. Also, the interns underwent the greatest amount of stress during their clinical rotation in Medicine $(78.8 \%)$, whereas the lowest amount of stress was observed during rotation in Emergency (58.3\%) (7). Another study of tertiary care hospitals of Peshawar, focused on the prevalence of bullying among postgraduate medical trainees, the results of which were staggering. The most common form of bullying was found to be work overload ( $83 \%$ ) (8).

This study was conducted in the tertiary care hospitals of Karachi, Pakistan, and it aimed to assess the risk factors of psychological distress among the currently working house officers (2016-2017). It is envisaged that the information gathered via this research will highlight measures which can be used to improve the working and personal lives of house officers in order to overcome the obstacles that pose stress. The ultimate goal being well functioning doctors and therefore provision of optimal health care.

\section{Methodology}

We conducted this cross-sectional study from October 2016 to March 2017 on a non-probability convenient sample of 384 house officers from three tertiary care hospitals of Karachi, Pakistan. We used $47.9 \%$ as the anticipated frequency of stress according to a study conducted in Karachi in 2013 (7) and calculated our sample size with confidence level 95\%. Our data comprises of 150 House Officers from CHK, 89 from JPMC and 76 from Abbasi Shaheed Hospital. A total of 315 participants returned the questionnaire. The questionnaire comprised of demographic data, 10 -items perceived stress scale, and 12-items list of potential stressors. The perceived stress was measured using the perceived stress scale (PSS-10). The PSS has an internal consistency of 0.85 (Cronbach ? co-efficient) and test-retest reliability of 0.85 . It assesses the degree to which participants evaluate their lives as being stressful during the past month. It is sensitive to the nonoccurrence of events as well as to the ongoing life circumstances. (15) PSS-10 scores are obtained by reversing the scores on four positive items, for example, $0=4,1=3,2=2$, and so on and then summing across all 10 items. Four out of the 10 items of PSS-10 are considered positive $(4,5,7 \& 8)$ and the remaining six as negative $(1,2,3,6,9 \& 10)$, representing self-efficacy and perceived helplessness, respectively. The scale yielded a single score with high scores indicating higher levels of stress and lower levels indicating lower levels of stress. The PSS-10 has a possible range of scores from 0 to 40 . The upper two and lower two quartiles were combined (20 being the operational cutoff value for the upper bound) and were labeled as stressed and not stressed, respectively. The potential stressors included were derived by reviewing the literature and by informal discussion with a group of house officers. A total of 12 sources of stress were listed. The severity of each stressor was measured using a five-point Likert scale ranging from always (1) to never (5). The data were analyzed using SPSS 22.0 for Windows (SPSS. Inc., Chicago, USA). The mean score of perceived stress was calculated. The percentages and mean scores with standard deviation were calculated for stressors. To calculate differences of continuous variables by gender of house officer for stressors by assuming the equal interval between different scores of Likert Scale. A pvalue of $<0.05$ was considered significant.

\section{Results}

Our cross-sectional hospitalized study was carried out among house officers working in CHK, JPMC, and Abbasi Shaheed Hospital. A total of 384 house officers were approached, out of whom 315 (82\%) participated. Out of 315, $94(29.8 \%)$ were males and $221(70.2 \%)$ were females. The mean age was $23.97(S D=0.777)$. Among 315,115 (36.50\%) were found to be under stress of whom $24(20.86 \%)$ were males and $91(79.13 \%)$ were females (Table 1). Non-stressed house officers were 200 (63.49\%), comprising $70(35 \%)$ males and $130(65 \%)$ females. A significant association between stress and gender was found ( $p$ value $<0.05$ ). Amongst 315 house officers, 291 were Muslims, 8 were Christians and 16 were Hindus. Amongst stressed house officers, 105 $(91.30 \%)$ were Muslims, 03 (2.6\%) were Christians and $07(6.08 \%)$ were Hindus. Amongst non-stressed house officers, 186 (93\%) were Muslims, 05 (2.5\%) were Christians and 09 (4.5\%) were Hindus (Table 1). No significant association between stress and religion was found ( $p$ value $>0.05$ )

Amongst 315 house officers, 265 were living with family, 20 with relatives, 15 in hostel and remaining 15 were living alone. Amongst stressed house officers 103 were living with family, 06 with relatives, 03 in hostel and remaining 03 were living alone. Amongst nonstressed house officers, 162 were living with family, 14 with relatives, 12 in hostel and remaining 12 were living alone (Table 1). No significant association between stress and residence was found ( $p$ value $>0.05$ ).

Out of 315 house officers, 234 were single, 48 engaged, 33 married. Highest stress was found amongst singles (not involved in any relationship) $82(71.3 \%)$, least amongst married $14(12.17 \%)$, and amongst engaged $19(16.5 \%)$ were under stress (Table 1). No significant association between stress and relationship status was found ( $p$ value >0.05) (Table $3 b$ ). Among all the participants, 150 house officers belonged to $\mathrm{CHK}$ (47.61\%), 89 were from JPMC $(28.25 \%)$ and 76 from Abbasi $(24.12 \%)$ (Table 1). No significant association between stress and working hospital was found ( $p$ value $>0.05$ ). 
Table 1. Relationship of Stressed and Non-Stressed House Officers with Gender, Practicing Hospital, Religion, Residence and Relationship Status

\begin{tabular}{|l|l|l|l|l|}
\hline Category & & Stress & Non-stress & Total \\
\hline Gender & Male & 24 & 70 & 94 \\
\hline & Female & 91 & 130 & 221 \\
\hline Practicing Hospital & Civil & 50 & 100 & 150 \\
\hline & JPMC & 36 & 53 & 89 \\
\hline & Abbasi & 29 & 47 & 76 \\
\hline Religion & Muslim & 105 & 186 & 291 \\
\hline & Christian & 3 & 5 & 8 \\
\hline & Hindu & 7 & 9 & 16 \\
\hline Residence & Family & 103 & 162 & 265 \\
\hline & Relatives & 6 & 14 & 20 \\
\hline & Hostel & 3 & 12 & 15 \\
\hline & Alone & 3 & 12 & 15 \\
\hline Relationship & Single & 82 & 152 & 234 \\
\hline & Engaged & 19 & 29 & 48 \\
\hline & Married & 14 & 19 & 33 \\
\hline
\end{tabular}

Non-parametric independent samples median test shows $p$ value $>0.05$, thus no association between gender and stressors was found. In $\mathrm{CHK}$, the stressed were $50(43.47 \%)$ and non-stressed $100(50 \%)$; in JPMC, stressed were found $36(31.30 \%)$ and nonstressed $53(26.5 \%)$; and in Abbasi, stressed were identified $29(25.21 \%)$ and non-stressed $47(23.5 \%)$ The mean PSS score in the study population was 17.91 (SD $=4.45$ ) with the median of 18.00. The 10-question survey sample responses evaluating stress level via PSS-10 scale are given in (Table 2).

Table 2. House Officers' Responses to PSS-10 Scale

\begin{tabular}{|l|c|c|c|c|c|}
\hline \multicolumn{1}{|c|}{ PSS 10 } & Never & Seldom & Sometimes & Often & Always \\
\hline $\begin{array}{l}\text { 1. In the last month, how } \\
\text { often have you been upset } \\
\text { because of something that } \\
\text { happened unexpectedly? }\end{array}$ & $46(14.6 \%)$ & $64(20.3 \%)$ & $79(25.1 \%)$ & $78(24.8 \%)$ & $48(15.2 \%)$ \\
\hline $\begin{array}{l}\text { 2. In the last month, how } \\
\text { often have you felt that you } \\
\text { were unable to control the } \\
\text { important things in your life? }\end{array}$ & $45(14.3 \%)$ & $81(25.7 \%)$ & $110(34.9 \%)$ & $41(13.0 \%)$ & $38(12.1 \%)$ \\
\hline $\begin{array}{l}\text { 3. In the last month, how } \\
\text { often have you felt nervous } \\
\text { and "stressed"? }\end{array}$ & $44(14.0 \%)$ & $29(9.2 \%)$ & $67(21.3 \%)$ & $84(26.7 \%)$ & $91(28.9 \%)$ \\
\hline $\begin{array}{l}\text { 4. In the last month, how } \\
\text { often have you felt confident } \\
\text { about your ability to handle } \\
\text { your personal problems? }\end{array}$ & $49(15.6 \%)$ & $97(30.8 \%)$ & $67(21.3 \%)$ & $52(16.5 \%)$ & $50(15.9 \%)$ \\
\hline $\begin{array}{l}\text { 5. In the last month, how } \\
\text { often have you felt that } \\
\text { things were going your way? }\end{array}$ & $123(39.0 \%)$ & $90(28.6 \%)$ & $49(15.6 \%)$ & $30(9.5 \%)$ & $23(7.3 \%)$ \\
\hline $\begin{array}{l}\text { 6. In the last month, how } \\
\text { often have you found that } \\
\text { you could not cope with all } \\
\text { the things that you had to do? }\end{array}$ & $128(40.6 \%)$ & $102(32.4 \%)$ & $37(11.7 \%)$ & $31(9.8 \%)$ & $17(5.4 \%)$ \\
\hline $\begin{array}{l}\text { 7. In the last month, how } \\
\text { often have you been able to } \\
\text { control irritations in your } \\
\text { life? }\end{array}$ & $117(37.1 \%)$ & $69(21.9 \%)$ & $59(18.7 \%)$ & $29(9.2 \%)$ & $41(13.0 \%)$ \\
\hline $\begin{array}{l}\text { 8. In the last month, how } \\
\text { often have you felt that you } \\
\text { were on top of things? }\end{array}$ & $37(11.7 \%)$ & $40(12.7 \%)$ & $71(22.5 \%)$ & $79(25.1 \%)$ & $88(27.9 \%)$ \\
\hline $\begin{array}{l}\text { 9. In the last month, how } \\
\text { often have you been angered } \\
\text { because of things that were } \\
\text { outside of your control? }\end{array}$ & $27(8.6 \%)$ & $36(11.4 \%)$ & $82(26.0 \%)$ & $104(33.0 \%)$ & $66(21.0 \%)$ \\
\hline $\begin{array}{l}\text { 10. In the last month, how } \\
\text { often have you felt } \\
\text { difficulties were piling up so } \\
\text { high that you could not } \\
\text { overcome them? }\end{array}$ & $99(31.4 \%)$ & $115(36.5 \%)$ & $68(21.6 \%)$ & $21(6.7 \%)$ & $12(3.8 \%)$ \\
& & & & & \\
\hline
\end{tabular}

Stress factors evaluated by the house officers are shown in (Table 3). Top stressors were hesitancy to take on tasks, lack of stress-management guidance, lack of receiving salary on time, lack of satisfaction with salary, language barrier and lack of paramedical staff cooperation.

Among female house officers, hesitancy for tasks, lack of receiving stress-management guidance, not being paid on time, lack of satisfaction with salary, lack of paramedical staff cooperation and language barrier, job being affected on health, noticing change in eating habits were major stressors (their means being in the range of 0.00-3.00).

Male doctors reported hesitancy for tasks, lack of receiving stress-management guidance, not being paid on time, lack of satisfaction with salary, appreciation for work, lack of paramedical staff cooperation and language barrier as the sources causing most stress (their means being in the range of 0.00-3.00), whereas the least stress was reported due to being bullied by senior doctors, not able to get along with colleagues and fear of transmissible diseases and job being affected on health.

Table 3. List of Stressors Perceived by the House Officers

\begin{tabular}{|l|l|l|l|l|l|}
\hline Descriptive Statistics & $\mathrm{N}$ & Min. & Max. & Mean & $\begin{array}{l}\text { Std. } \\
\text { Deviation }\end{array}$ \\
\hline & & & & & \\
\hline Not get along with collegues & 315 & 1 & 5 & 3.62 & 1.154 \\
\hline Job as an HO is beginning to deteriorate health & 315 & 1 & 5 & 2.84 & 1.334 \\
\hline Change in eating habits & 315 & 1 & 5 & 2.69 & 1.269 \\
\hline Hesitant to take task & 315 & 1 & 5 & 3.80 & 1.146 \\
\hline Not satisfied with salary & 315 & 1 & 5 & 1.79 & 1.195 \\
\hline Not paid on time & 315 & 1 & 5 & 1.57 & 1.108 \\
\hline Lack of paramedical staff co-operation & 315 & 1 & 5 & 2.54 & 1.190 \\
\hline Fear of transmissible disease & 315 & 1 & 5 & 3.40 & 1.377 \\
Language barrier prove to be a hindrance & 315 & 1 & 5 & 2.57 & 1.248 \\
\hline Being bullied by senior doctors & 315 & 1 & 5 & 3.43 & 1.243 \\
\hline Not getting appreciation for work & 315 & 1 & 5 & 2.83 & 1.302 \\
\hline $\begin{array}{l}\text { Not received any guidance pertaining to stress } \\
\text { Management and selfcare }\end{array}$ & 315 & 1 & 5 & 1.37 & .877 \\
\hline
\end{tabular}

0.00-1.00(causing very high stress), 1.01-2.00(causing high stress), 2.01-3.00(causing moderate stress), 3.01-4.00(causing very low stress), 4.01-5.00(causing no stress)

According to non-parametric independent samples median test, significant difference for stressors by gender was found their job having an effect on their health, change in eating habits and lack of paramedical staff cooperation $(P<0.05)$. Thus, a significant association was found for these stressors in male and female house officers (Table 4). 
Table 4 Non Parametric Independent Sample Median Test showing Significant Difference for Specific Stressors

\begin{tabular}{|c|c|c|c|c|}
\hline & & & & \\
\hline & Null Hypothesis & Test & Sig. & Decision \\
\hline 1 & $\begin{array}{l}\text { The medians of not get along with } \\
\text { oollegues are the same aoross } \\
\text { oategories of gender. }\end{array}$ & $\begin{array}{l}\text { Independent- } \\
\text { Samples } \\
\text { Median Test }\end{array}$ & .453 & $\begin{array}{l}\text { Retain the } \\
\text { null } \\
\text { hypothesis. }\end{array}$ \\
\hline 2 & $\begin{array}{l}\text { The medians of job as an ho is } \\
\text { beginning to deteriorate health are } \\
\text { the same aoross oategories of } \\
\text { gender. }\end{array}$ & $\begin{array}{l}\text { Independent } \\
\text { Samples } \\
\text { Median Test }\end{array}$ & .004 & $\begin{array}{l}\text { Rejeot the } \\
\text { nuil } \\
\text { hypothesis. }\end{array}$ \\
\hline 3 & $\begin{array}{l}\text { The medians of ohange in eating } \\
\text { habits are the same aoross } \\
\text { oategories of gender. }\end{array}$ & $\begin{array}{l}\text { Independent } \\
\text { Samples } \\
\text { Median Test }\end{array}$ & .014 & $\begin{array}{l}\text { Rejeot the } \\
\text { nuil } \\
\text { hypothesis. }\end{array}$ \\
\hline 4 & $\begin{array}{l}\text { The medians of hesistant to take } \\
\text { task are the same aoross } \\
\text { oategories of gender. }\end{array}$ & $\begin{array}{l}\text { Independent } \\
\text { Samples } \\
\text { Median Test }\end{array}$ & .059 & $\begin{array}{l}\text { Retain the } \\
\text { null } \\
\text { hypothesis. }\end{array}$ \\
\hline 5 & $\begin{array}{l}\text { The medians of not satisfied with } \\
\text { salany are the same aoross } \\
\text { oategories of gender. }\end{array}$ & $\begin{array}{l}\text { Independent- } \\
\text { Samples } \\
\text { Median Test }\end{array}$ & .900 & $\begin{array}{l}\text { Retain the } \\
\text { null } \\
\text { hypothesis. }\end{array}$ \\
\hline 6 & $\begin{array}{l}\text { The medians of not paid on time a } \\
\text { the same aoross oategories of } \\
\text { gender. }\end{array}$ & $\begin{array}{l}\text { lodependent. } \\
\text { Samples } \\
\text { Median Test }\end{array}$ & .817 & $\begin{array}{l}\text { Retain the } \\
\text { null } \\
\text { hypothesis. }\end{array}$ \\
\hline 7 & $\begin{array}{l}\text { The medians of laok of paramedio } \\
\text { staft oo-operation are the same } \\
\text { aoross oategories of gender. }\end{array}$ & $\begin{array}{l}\text { Ahdependent } \\
\text { Samples } \\
\text { Median Test }\end{array}$ & .023 & $\begin{array}{l}\text { Rejeot the } \\
\text { nuil } \\
\text { hypothesis. }\end{array}$ \\
\hline 8 & $\begin{array}{l}\text { The medians of fear of transmissibl } \\
\text { dise ase are the same aoross } \\
\text { oategories of gendet. }\end{array}$ & $\begin{array}{l}\text { Imdependent- } \\
\text { Samples } \\
\text { Median Test }\end{array}$ & .112 & $\begin{array}{l}\text { Retain the } \\
\text { null } \\
\text { hypothesis. }\end{array}$ \\
\hline 9 & $\begin{array}{l}\text { The medians of language barrier } \\
\text { prove to be a hindranoe? are the } \\
\text { same aoross oategories of gender. }\end{array}$ & $\begin{array}{l}\text { Independent } \\
\text { Samples } \\
\text { Median Test }\end{array}$ & .078 & $\begin{array}{l}\text { Retain the } \\
\text { null } \\
\text { hypothesis. }\end{array}$ \\
\hline 10 & $\begin{array}{l}\text { The medians of being bullied by } \\
\text { senior dootors? are the same } \\
\text { aoross oategories of gender. }\end{array}$ & $\begin{array}{l}\text { Independent } \\
\text { Samples } \\
\text { Median Test }\end{array}$ & .839 & $\begin{array}{l}\text { Retain the } \\
\text { nuII } \\
\text { hypothesis. }\end{array}$ \\
\hline 11 & $\begin{array}{l}\text { The medians of not getting } \\
\text { appreoiation for wotk are the same } \\
\text { aoross oategories of gender. }\end{array}$ & $\begin{array}{l}\text { Independent } \\
\text { Samples } \\
\text { Median Test }\end{array}$ & .450 & $\begin{array}{l}\text { Retain the } \\
\text { null } \\
\text { hypothesis. }\end{array}$ \\
\hline 12 & $\begin{array}{l}\text { The medians of not received any } \\
\text { guidanoe pertaining to stress } \\
\text { management and selfoare are the } \\
\text { same aoross o ategories of gender. }\end{array}$ & $\begin{array}{l}\text { Independent- } \\
\text { Samples } \\
\text { Median Test }\end{array}$ & .353 & $\begin{array}{l}\text { Retain the } \\
\text { null } \\
\text { hypothesis. }\end{array}$ \\
\hline
\end{tabular}

Factors like increased hesitancy to take on tasks and increased tendency to make errors were found to have an impact on clinical performance $(P$ value $<0.05)$. House officers of Surgery ward 71(22.5\%) participated the most in the study, medicine $65(20.6 \%)$ being the second most common. Other participants were Pediatrics 42(13.3\%) and Gynecology 45(14.28\%). The substantial number of stressed house officers in descending order was found in Medicine (27.82\%), Surgery (20.87\%), Gynecology (17.39\%), Pediatrics $(17.39 \%)$, ENT $(6.95 \%)$; and of non-stressed house officers was in Surgery $(23.5 \%)$, Gynecology and Obstetrics (13.5\%), Dermatology (12\%), Pediatrics (11\%) (Fig 1, Table 5). Significant association between stress and ward postings was found ( $p$ value $>0.05$ ).

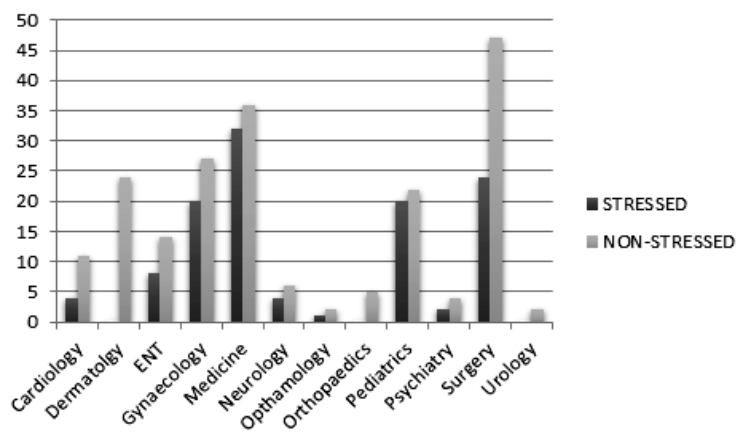

Figure 1 Bar Chart showing relation of Ward Posting with Stressed Non-Stressed House Officers
Table 5. Relationship of Current Ward Posting with Stressed and Non-Stressed House Officers

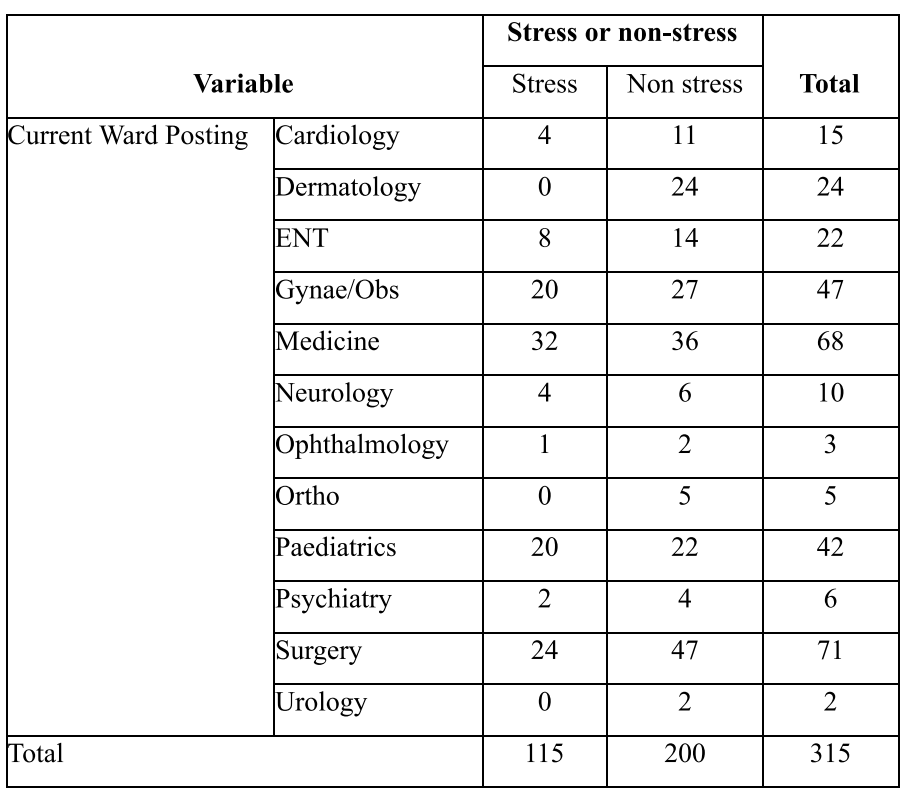

\section{Discussion}

The basic aim of conducting this study was to assess the risk factors of stress among house officers in three tertiary care hospitals of Karachi. Our study also covers the prevalence of stress among different wards which has so far not been mentioned in any of the previous studies in our country as per our knowledge.

According to the results of our study, $36.5 \%$ of the house officers were under stress which is in contrast to the result of another study conducted among house officers in two of the government tertiary care hospitals that we approached, CHK and JPMC in the year 2013. Their results stated that around $47.9 \%$ were found to be under stress (7) which is a figure that has shown a decrease within two years. More females $(79.13 \%)$ are found under stress that means female medical trainees are more liable to have a stressful life. This gender variation could be because females outnumber their male counterpart in medical schools, besides they also have to put more efforts to keep a balance between household chores and workload at hospital. A similar study conducted in different Saudi medical college hospitals reported that $84 \%$ females and $66.5 \%$ male have a stressful life which might be due to the high prevalence of depression among females in general population (2).

Our study is also in contrast to the findings in another study conducted on South Indian interns of a tertiary care hospital, which showed that out of 93 interns, $45.2 \%$ perceived stress affecting their quality of life (10), a figure higher than our results. This could be because of comparatively less working hours for our house officers as compared to those in the setup outside our country. Our findings are also lower than the stress in undergraduate medical students, i.e., $52.3 \%$ as reported by a study conducted in Lahore, Pakistan (9), which may 
be due to gaining experience by means of problemfocused approach towards patients along with time management and lifestyle modification to adjust in work structure. For learning and acquisition of skills, stress polishes them into mature and determined health practitioner (10).

In account of the perceived stress scale, which has been validated and widely used in many domains (11) we have selected perceived stress scale as a parameter to measure stress level. As compared to major contributors to stress among our study participants, the factors contributing more towards stress found in a Malaysian study are fears of making mistakes that can result in serious consequences, work overload, working with uncooperative colleagues, doing work that is mentally straining and feeling of not being paid enough (6).

The stress prevalence is higher in female, and the contributing factors which affect female population more frequently are job affecting health and change in eating habits. This shows that females have more difficulty in managing time, and thus their health becomes affected. The factor found more often in male population is lack of appreciation for work. This association links to the fact that male are the sole bread earners of the family and especially appreciation from the seniors in their field holds more value in terms of further success in their career. Another study found long working hours, poor work-life balance and the inability to commit to personal and social activities outside of work associated with stress. However there is conflicting opinion on the implementation of work hour limits at an organizational level reducing the prevalence of stress (12). According to one study, job stress is one of the most important workplace health risks for employees, and job satisfaction has been considered as a crucial factor in the provision of high quality services and superior performance at hospitals (13).

As per the findings of our research, house officers who showed higher level of participation are from surgical wards $(22.5 \%)$ followed by Medicine, Pediatrics and Gynecology wards. The maximum number of house officers and general doctors is posted in these wards because of a very high patient influx. The stress level is found to be maximum in the Medicine ward followed by Surgery, Gynecology and Paediatrics apparently because of the longest working hours, calls, and workload. ENT, Plastic Surgery, Ophthalmology and Cardiology are next to these wards respectively. This is also established by Sameer-ur-Rehman et al in a research conducted on the residents of two tertiary care hospitals of Karachi (Ziauddin University Hospital and AKUH), showing a positive correlation between working hours and job satisfaction (14). Their results show an almost similar level of stress among both Medicine and Surgery residents $(56.3 \%)$ which contrasts with our study as Medicine unit posted house officers have more stress as compared to Surgical units. Similarly, a Saudi medical college hospital reports the highest level of stress found during clinical rotations of Medicine $(78.8 \%)$, followed by Surgery $(74.7 \%)$, Pediatrics $(72.4 \%)$, Obstetrics and Gynecology $(70.1 \%)$ and Emergency (58.3\%). This however contrasts to our findings as on general the maximum stress from the clinical rotations in our study is only $47.62 \%$ in Pediatrics wards (2).

\section{Limitations}

The present study is only confined to house officers, who have very limited experience and exposure to this field; and also the study is limited to public sector hospitals only, hence the findings cannot be applied to the general population of doctors.

\section{Conclusion}

There is a high level of perceived stress among house officers in CHK, JPMC and Abbasi Shaheed Hospital, Karachi. The findings show that female house officers perceive higher stress as compared to males and hence, may need more support. Therefore, appropriate steps are needed for stress management in terms of preventive rather than curative strategy. The risk factors identified for stress should be addressed. A policy and plan may be devised to provide psychosocial support and counseling to reduce stress during the internship, and make the seniors and staff to work in collaboration and support them to work in stress free environment.

\section{References}

1 Kauts A, Sharma N. Effect of yoga on concentration and memory in relation to stress. ZENITH international journal of multidisciplinary research. 2012;2(5):1-4.

2 al Zunitan M, al Dehaim M. Prevalence of stress in junior doctors during their internship training: a cross-sectional study of three Saudi medical colleges' hospitals. Neuropsychiatric disease and treatment. 2014;10:1879-86.

3 Haqqi S, Areeb SB, Haseeb A, Ali NF, Hashim H. The prevalence of depression among resident doctors in a teaching hospital. Pak J Med Dent. 2013;2:16-20.

4 O'Donnell M, Noad R, Boohan M, Carragher A. Foundation programme impact on junior doctor personality and anxiety in Northern Ireland. The Ulster medical journal. 2012 Jan;81(1):19.

5 Weigl M, Hornung S, Petru R, Glaser J, Angerer P. Depressive symptoms in junior doctors: a follow-up study on work-related determinants. International archives of occupational and environmental health. 2012 Jul 1;85(5):559-70.

6 Yusoff MS, Jie TY, Esa AR. Stress, stressors and coping strategies among house officers in a Malaysian hospital. ASEAN Journal of Psychiatry. 2011;12(1):85-94.

7 Maroof Hassan TH, Ahmed SM, Fraz TR, Rehmat Z. Perceived stress and stressors among house officers. Indian journal of occupational and environmental medicine. 2014 Sep;18(3):145. 
8 Hussain SS, Rahim R. Bullying of postgraduate medical trainees in tertiary care hospitals. Journal of Postgraduate Medical Institute (Peshawar-Pakistan). 2014 Jul 25;28(3):34-37.

9 Imran N, Tariq KF, Pervez MI, Jawaid M, Haider II. Medical Students' Stress, Psychological Morbidity, and Coping Strategies: a CrossSectional Study from Pakistan. Academic Psychiatry. 2016 Feb 1;40(1):92-96.

10 Chandramouleeswaran S, Edwin NC, Braganza D. Job stress, satisfaction, and coping strategies among medical interns in a South Indian tertiary hospital. Indian journal of psychological medicine. $2014 \mathrm{Jul} ; 36(3): 308$.

11 Cavanagh JF, Shackman AJ. Frontal midline theta reflects anxiety and cognitive control: meta-analytic evidence. Journal of PhysiologyParis. 2015 Jun 30;109(1):3-15.

12 Gramstad TO, Gjestad R, Haver B. Personality traits predict job stress, depression and anxiety among junior physicians. BMC medical education. 2013 Nov 9;13(1):150.

13 Kakkos N, Trivellas P. Investigating the link between motivation, work stress and job performance. Evidence from the banking industry. In8th International Conference on Enterprise Systems, Accounting and Logistics $2011 \mathrm{Jul}$ (pp. 408-428).

14 Kumar R, Siddiqui N, Shahid Z, Syed S, Kadir M. Stress, job satisfaction and work hours in medical and surgical residency programmes in private sector teaching hospitals of Karachi, Pakistan. JPMA. The Journal of the Pakistan Medical Association. 2012 Oct;62(10):1109-12.

15 Lee EH. Review of the psychometric evidence of the perceived stress scale. Asian Nursing Research. 2012 Dec 31;6(4):121-27. 